\title{
INTRODUCTION OF “A DISABILITY CERTIFICATE” FOR SRI LANKAN CIVIL COMPENSATION CASES
}

Senanayake S.M.H.M.K.

\author{
Teaching Hospital, Anuradapura, Sri Lanka
}

\begin{abstract}
In Sri Lanka, obtaining medical evidence for civil compensation cases is difficult and expensive for the plaintiff because of compulsory transfer of government medical officers in every four years. Therefore, Judicial Medical Officers (JMO) are frequently summoned by Judges and prosecutors because a JMO has examined the patient and is trained to give evidence in

Respondent party will also have the opportunity to request a new examination and a new certificate by different medical experts. This certificate will educate judiciary, prosecution and defense. It will expedite the civil compensation procedure, minimize the burden on clinicians, prepare medical personals to give oral evidence and minimize the expenses for the victim.
\end{abstract} courts. The respondent party usually opposes stating that JMO had only medico-legally examined the patient, hence, is not an expert to describe the ordinary outcome of the patient. However, lot of compensation cases had been concluded by granting compensations from medical evidence of JMO who prepared evidence with reexamination of the patient and consulting clinicians. Introduction of a detailed medical certificate which could be named "disability certificate for compensation purposes" for all civil compensation cases to help courts is a timely necessity in Sri Lanka. The certificate should include the history of the incident, initial examination, diagnosis, summery of the management, condition at the time of discharge, summery of clinic follow-up, all disabilities (temporary partial, temporary total, permanent total and permanent partial) with relevant durations, outcome of each disability, effect of each disability on his earnings and personal life. This certificate is to be signed by the clinician/s and JMO, issued when requested by the patient before filling the compensation court case and if necessary before the trial date. JMO is to give oral evidence first, based on this report and if required, clinician is to be summoned only to address unsolved issues, so to minimize unnecessary harassments to large number of patients managed by the clinician.

Key Words: Disability certificate, civil compensation

Corresponding author:

dilruksena62@yahoo.co.uk

\section{INTRODUCTION}

A civil compensation case in the District Court is the final pathway available for a victim of any damage due to criminal act or civil act to obtain monetary compensation for his loss. This action belongs to the civil law and the plaintiff has to bear the expenditure for the case which includes charges for lawyers and medical witnesses. Unfortunately, in Sri Lanka obtaining medical evidence for civil compensation cases in district courts is difficult and expensive for the plaintiff because of compulsory transfer of government medical officers in every four years. Therefore, Judicial Medical Officers (JMO) are frequently summoned by Judges and prosecutors because a JMO had examined the patient and is trained to give oral evidence in courts. The respondent party usually objects evidence of JMO stating that JMO had only medico-legally examined the patient and, hence, is not an expert to describe the 
outcome of the patient's clinical conditions. However, several compensation cases had been concluded by granting compensations with medical evidence from JMO who gets prepared with re-examination of the patient, discussions with the clinician and literature survey before the court trial. In a compensation trial, period of hospitalization, period of rehabilitation, residual permanent disabilities and effects on those disabilities on the professional life are discussed in length to decide the amount of compensation. Though is no residual permanent disability due to full recovery, victim will be awarded a compensation relevant for the period he/she was under treatments.

In some developed countries, clinical forensic medicine curriculum has a major module under the title of "Workers compensation examination and assessments" . Sri Lanka also needs more attention about medical evidence in civil compensation cases such as a module in the postgraduate curriculums, detailed medical reports of disability and formulating "disability scales".

In developed countries varing scales are used to assess the progression of the illness which includes subjective assessments of the patient and objective assessments of the clinician. All the professional associations of clinical medical specialists will have the duty to formulate disability scales for all common disabilities. There should be a common agreement among the medical professionals about the degree of a particular disability and the effect on the activities of the patient. Effects of different disabilities on patient's profession, day to day activities and leisure activities need to be identified during the period of treatment to evaluate the recovery. Present situation and future developments of the medical evidence in compensation cases are discussed in this article.

\section{Present situation of medical evidence in compensation cases at civil courts of Sri Lanka}

Civil compensation cases are filled by victims of road traffic accidents, assaults, injured during the occupation, etc. Medical evidence is vital for the judgment of the compensation. Clinician who treated the patient is bound to give written and oral evidence for civil courts on a payment by prosecution or responding party. Civil courts have the power to issue warrants for the medical officers who do not comply. However, in Sri Lanka, government medical officers are transferred out of the working station in every four years. When the compensation case is heard, clinician usually had been transferred to a distant hospital. Victim has to pay significant amount of payment to obtain medical evidence which includes the clinician's travelling expenses and his professional charges. A financially challenged victim can file a case with the help of legal aid commission (government institution for free legal advices) so that medical evidence is given free by JMO. Judiciary and ministry of health are expected to formulate rules about reasonable charges for medical evidence. Clinicians are not pleased to appear in courts as they cannot treat their patients during that particular day. Hence, Judges do not usually issue warrants for clinicians due to the extensive service they provide to their patients. When clinician is not available, prosecution and judges prefer to obtain medical evidence from the judicial medical officer (JMO). It is reasonable as the JMO had seen the patient and is well trained to give evidence in the courts. Lack of medical certificates and medical evidence about disabilities is a worldwide problem, therefore, majority of victims accept modified solutions proposed by insurance companies ${ }^{2}$.

Defense or responding party usually objects evidence given by the JMO on the basis that JMO had only performed a medico-legal examination, JMO had not treated the patient and JMO does not know about the outcome of the patient. When a summon is received from the civil court, JMO will re-examine the patient, will collect all medical documents including bed head ticket and clinic notes, study medical literature and discuss with the relevant clinician/s about the patient's condition as preparation. 
JMO's or clinician's duty in a civil compensation trial at present includes:-

1. To present the original medical documents of the hospital (bed head ticket, investigation reports and clinic notes) with certified photocopies.

2. Briefly explain the bed head ticket including the clinical history, examination findings, investigation results, diagnosis and management.

3. If medico-legal examination had been performed, JMO will present the medicolegal report including history, injuries and compatibility of those two.

4. Explaining the clinic follow up with clinic notes.

5. Explain the natural history of medical conditions.

6. Explain the usual outcome of the illnesses with the treatments.

7. Explain the temporary and permanent disabilities of each injury with the time period.

8. Any modifying factors of outcome such as default treatments, concurrent illnesses, negligence of the patient.

9. Explain possible future management.

10. Explain necessary life modifications.

Above mentioned facts can be explained to courts by any medical personal representing the head of the institution, who will prepare with the patient's conditions. However, in some cases, clinician is essential to explain about the outcome of the particular patient. Examples for such issues are; Why there was no improvement with the best available treatments in this patient? What will be the long term outcome of this disability in this particular patient? Was the patient given best possible treatments available in the hospital? Why that particular treatment was not given?

JMO will explain medical conditions and outcomes in general according to the medical literature but clinician who treated will explain the individual conditions of the particular patient according to the patient's condition and according to his experience. But such individualized explanation is needed infrequently.
Currently when the clinician or JMO who examined the patient are not available, court orders the nearby clinician or JMO to produce a new report after examining the patient and explaining previous medical documents such as bed head ticket and clinic documents to the court. Court may even appoint a medical board $^{3}$. Court trial is heard few years later and the medical evidence is expressed according to the medical documents. Therefore, medical evidence of the JMO and clinician are not much different on facts observed in the patient and explanation of medical theories. However, opinion of the JMO will be the general opinion about any patient suffering from a similar condition while opinion of the treated clinician will be the specific and more focused about one particular patient. In most of the compensation cases, facts and knowledge of the medical conditions are sufficient for the judges to deliver the judgments. Absence of clinician's oral evidence will not make a significant difference in the judgments in most of the cases.

\section{Required developments in medical evidence}

To minimize the burden on clinicians and large number of patients under the care of such clinicians, Sri Lankan authorities needs to introduce of a complete medical report for civil compensation purposes.

This certificate can be named as "Disability Certificate for Compensation Purposes (DCCP)".

\section{DCCP needs to contain:-}

1. history of the incident

2. findings of initial examination with injury description

3. diagnosis

4. compatibility of the history and injuries

5. summery of the medical management

6. clinical condition at the time of discharge

7. summery of clinic follow-up

8. all temporary and permanent disabilities

9. outcome of each disability 
10. effect of each disability on his professional life and personal life

11. progression of each disability

12. possible future managements

13. necessary life modifications

14. available better treatment options inside and outside country for further management

\section{When this DCCP is issued?}

All the patients who plan to file a civil compensation case are informed to get registered for civil compensation certificate program in JMO's office in the hospital. A file for each patient is maintained by the JMO which includes the history, injury description, certified photocopy of the bed head ticket, copy of clinic notes, periodical joint examination reports of JMO and clinician, all types of disabilities (permanent total, permanent partial, temporary total, temporary partial), all the disabilities with the affected time period and progression. First the certificate will be issued on request of the patient before the case is filed. Based on this report, the prosecutor for the victim can learn the real physical and mental condition of the client and can request a reasonable amount of compensation relevant for the disability. There will be no need to have medical consultation with the clinician prior to file the case. Second report will be issued only if requested, just before the trial, to show the progression of the disabilities. When defense or judge wants a separate certificate, court can order a new certificate from a separate group of clinician/s and JMO about the present condition and the future progression of disabilities. Practically it is easier to request a detailed medical certificate than finding a defense medical witness. In all above situations, JMO will prepare the certificate after discussing with the clinician/s and it will be signed by the JMO and all involved clinicians.

\section{Advantages of DCCP are:-}

1. During the initial treatment period, patients inform about their future ambition for legal actions. Therefore, doctors can collect all necessary medical evidence and medical reports for the court case such as investigations and referrals. Forensic medicine specialist can handle the case instead of non-specialists (assistant judicial medical officers) to improve the quality of medical evidence in the trial ${ }^{4}$. Usually bed head tickets are destroyed after five years in government hospitals. However, bed head tickets which are marked as "medico-legal case" can be persevered up to 25 years because of involvement with judicial actions. Doctors can anticipate possible legal issues and be prepared for them.

2. Before the trial, prosecution and responding parties can obtain necessary knowledge about the condition of the victim from this report. Therefore, prior consultation with clinician is not necessary to file the case.

3. When prosecution and defense agree, case can be settled without oral evidence from medical witnesses because a detailed medical report is available with the amount of disability and future progression.

4. Prosecution, defense and judiciary have the opportunity to study the case and be prepared, based on the facts and opinion of the certificate.

5. If judiciary or defense needs second medical opinion about the victim's latest condition, a new certificate from another group of medical specialists can be requested. When opinions of second report and first report are equal, there will be no need to summon medical witnesses.

6. When taking the oral medical evidence, time duration in the witness box will be minimum and procedure is easy because of the medical report (written evidence).

7. This certificate can be used by insurance companies, government departments and administers of private factories also to grant compensations. Therefore, 
professional secrecy should be maintained strictly ${ }^{5}$.

8. A government fee will be decided for this certificate as well as for oral medical evidence. It will reduce the expenditure of the victim.

9. Because a detailed medical report with signatures of relevant clinician/s is available, JMO will give oral evidence first, based on this report and if required only the clinician will be summoned to answer difficult and specific issues of the case to minimize unnecessary harassments to large number of patients managed by the clinician.

10. Medical witness will attend the court with better preparation because JMO and clinician plan to provide best scientific evidence to court from the beginning.

\section{How to develop the DCCP?}

Ministry of health should arrange discussions with all relevant professional organizations and stake holders to formulate the structure of the certificate (DCCP), prepare a guideline and educate legal professionals and judiciary. Afterwards, academic bodies of medical specialists can formulate "Disability Evaluation Assessment Scales" for different conditions they manage ${ }^{6}$ or one common disability scale for entire body for any form of damage. Such scales will be followed to monitor the recovery of the patient during the treatment period. Records of periodically completed scales can be presented to courts to explain the patients recover states accurately.

\section{CONCLUSION}

All involved clinicians and JMO will prepare a disability certificate for compensation purposes containing all necessary information for compensation court cases including history, injuries, management, all forms of disabilities with outcome and the effect on victim's earning capacity and personal life. In civil compensation trials, first JMO can give oral evidence based on the certificate, and if necessary only clinician/s can give oral evidence to address unsolved issues. This certificate will educate judiciary, prosecution and defense from the beginning of the case. It will expedite the civil compensation procedure, minimize the burden on clinicians, prepare medical personals to give oral evidence and minimize the expenses of the victim.

\section{REFERENCES}

1. Philip S.L. BEH. Clinical Forensic Medicine: Much Scope for Development in Hong Kong. Medical sessions. 2002; 7 (1) 3-4.

2. Gullbring B, Månsson M, Walheim G. Insufficient legal rights of traffic accident victims: Insurance companies should force more active compensation claims. Lakartidningen. 2000. 97 (46):5318-21.

3. Senanayake SMHMK. Chasing the devil off: medicolegal issues related to indigenous treatments of a child. Sri Lanka Journal of Forensic Medicine, Science and Law 2015;6(1) 3-6

4. Von Livonius B, Pause H, Ulbig M. Ophthalmological assessment in procedures for disability benefits for the blind: Why medical certificates alone are insufficient. Ophthalmologe. 2015 Dec 17. [Epub ahead of print]

5. Mishra NN, Parker LS, Nimgaonkar VL, Deshpande SN. Disability certificates in India: a challenge to health privacy. Indian Journal for Medical ethics Ethics. 2012.9 (1):43-5.

6. Mohan I, Tandon R, Kalra H, Trivedi JK. Disability assessment in mental illnesses using Indian Disability Evaluation Assessment Scale (IDEAS). Indian Journal for Medical Researches. 2005 ;121(6):759-63. 